\title{
SciDoC
}

Infer, Interpret \& Inspire Science

\author{
International Journal of Dentistry and Oral Science (IJDOS) \\ ISSN: 2377-8075
}

\section{The Assessment Of Need For Suturing Following Maxillary Third Molar Extractions}

Research Article

Sathvika $\mathrm{K}^{1}$, Senthil Murugan. $\mathrm{P}^{2^{*}}$, Leelavathi $\mathrm{L}^{3}$

${ }^{1}$ Saveetha Dental College Saveetha Institute of Medical and Technical Sciences Saveetha university Chennai, India.

${ }^{2}$ Associate Professor, Department of Oral and Maxillofacial Surgery, Saveetha Dental College Saveetha Institute of Medical and Technical Sciences Saveetha University Chennai, India.

${ }^{3}$ Senior Lecturer, Department of Public Health Dentistry, Saveetha Dental College and Hospitals Saveetha Institute of Medical and Technical Science Saveetha University Chennai -77 , India.

\section{Abstract}

Background: Maxillary third molar extractions (MTME) are one of the most common procedures done in maxillofacial surgery. Nevertheless, there are general complications that arise with every surgery. The spectrum of complications ranges from post-operative pain to permanent nerve damage, fractures and infections.

Aim: In our study, we have aimed to understand why suturing had been done following MTME and to observe a predilection in age and gender. By attempting to do so, we may establish when suturing is required and if age and gender have a role to play. Materials And Methods: A retrospective cross-sectional study was conducted after reviewing and analysing the data from 86,000 patient records between June 2019 and March 2020. Patients with an established record of MTME were selected from the age group of (20-60) years. A Microsoft Excel data spreadsheet was used to collect data and was later exported to SPSS. Results: The females of the study population had a larger frequency for having undergone MTME (52.7\%) compared to the males $(47.3 \%)$ and lastly trans genders $(0.1 \%)$. The highest incidence of MTME was found in the age group of (31-40) years with $30.6 \%$ followed by (20-30) and (41-50) years with $26.9 \%$ each. (51-60) years had the least MTME done (15.6\%). There was a higher incidence of extracted 28 's than 18 's $(52.1 \%>47.9 \%)$. Sutures were placed only in $1.6 \%$ of the total cases due to tuberosity fractures that had occurred as a complication of MTME.

Conclusion: The placement of a suture following exodontia is not always mandatory, but when a complication such as a maxillary tuberosity fracture arises, suturing must be done. It is imperative to be equipped with the knowledge on how to manage possible complications, because even simple exodontias can prove to have fatal outcomes. Thus, further studies must be done to confirm our findings and to test other geographical locations and ethnicities.

Keywords: Exodontia; Maxillary Third Molar; Extraction; Maxillary Tuberosity Fracture; Suturing; Complications.

\section{Introduction}

Exodontia is the removal of a tooth from the dental alveolus in the alveolar bone. A tooth may be removed from the oral cavity for a variety of reasons such as tooth decay, infection, periodontitis, pericoronitis, prosthetics, cosmetics and in the past for prophylaxis $[23,35,11]$. Molar teeth are the most frequently extracted teeth [19] and the third molar is the most common molar extracted [30] followed by premolars in recent years [2]. Thus, third molar surgery is one of the most commonly performed procedures in maxillofacial surgery units [26]. Nevertheless, accurate planning and sound surgical skills are required as complications arise in general following any surgery $[24,12]$. The incidence of complications following third molar surgery ranges between 2.6\% to $30.9 \%[5,6]$. The spectrum of complications that could possibly occur range from expected post-operative pain and swelling to permanent nerve damage, mandibular fractures, maxillary tuberosity fractures, maxillofacial trauma, alveolar osteitis, life threatening infections and abscess formation $[13,14,7,17,33]$.

A suture is placed to hold body tissues together after an injury or a surgery and several studies have hinted that placing sutures

*Corresponding Author:

Dr. Senthil Murugan. P,

Associate Professor, Department of Oral and Maxillofacial Surgery, Saveetha Dental College Saveetha Institute of Medical and Technical Sciences Saveetha University Chennai, India. Tel: +919790869469

Email ID: senthilmuruganp.sdc@saveetha.com

Received: December 02, 2020

Accepted: January 21, 2021

Published: February 27, 2021

Citation: Sathvika K, Senthil Murugan. P, Leelavathi L. The Assessment Of Need For Suturing Following Maxillary Third Molar Extractions. Int J Dentistry Oral Sci. 2021;08(02):17751779. doi: http://dx.doi.org/10.19070/2377-8075-21000351

Copyright: Senthil Murugan. $\mathbf{P}^{\circ}$ 2021. This is an open-access article distributed under the terms of the Creative Commons Attribution License, which permits unrestricted use, distribution and reproduction in any medium, provided the original author and source are credited. 
increases post-operative pain [29, 33] and swelling when opposed to leaving the extraction site sutureless [9]. But sutures must be placed following surgical complications such as maxillary tuberosity fractures and mandibular fractures [4]. Third molar extractions are one of the most difficult teeth to extract, thus our study aims to highlight when and where suturing is needed and to pinpoint the age and gender in which maxillary third molar extractions are common in, such that we may better excel in our prophylactic, pre-operative anxiety [20], waste [22] and complication management standards [25].

\section{Materials and Method}

\section{Study Design and Setting}

This retrospective study examined the records of 86,000 patients who underwent treatment at Saveetha Dental College, Chennai during June 2019 to March 2020. Ethical approval was obtained from the Institutional Ethics Committee. The study population included patients who had undergone maxillary third molar extractions from the age of 20 years to 60 years. They were separated according to their sex, age and tooth number extracted and were checked for suture placements and complications. Mentally or physically disabled individuals were excluded from the study due to the difficulties in obtaining reviews.

\section{Data Collection}

The patient records of 86,000 patients who visited Saveetha Dental College from June 2019 to March 2020 were analysed and were used to identify 1836 patients in the hospital database who had undergone maxillary third molar extractions. Relevant data such as patient age, sex, tooth number extracted, complications and suture placement were recorded. Repeated patient records, incomplete entries and extractions with no history of reviews were excluded. The data obtained was then verified by an external reviewer.

\section{Statistical Analysis}

Data was recorded in Microsoft Excel 2016 (Microsoft Office 10) and was later exported to the Statistical Package for the Social Sciences for Windows. (Version 20.0, SPSS, Inc., Chicago, USA) and was subjected to statistical analysis.

\section{Results And Discussion}

The final dataset consisted of 1836 patients, predominantly of South Indian origin who had undergone left, right or both maxillary third molar extractions. There was a clear female predilection with the females having undergone $52.7 \%$ of the extractions, followed by males $(47.3 \%)$ and finally $0.1 \%$ of transgenders as inferred from Figure 2. The most number of maxillary third molar extractions was seen in the age group of (31-40) years with $30.6 \%$ of all the total extractions, followed by the age groups of (20-30) years and (41-50) years with $26.9 \%$ of the extractions each and lastly, $15.6 \%$ of the extractions in the age group of (51-60) years. There was also a predominance of tooth number where upper left third molars (28) were more commonly extracted than upper right third molars [18] $52.1 \%>47.9 \%$. Sutures were placed only in $1.6 \%$ of the total cases to contain the complication of maxillary tuberosity fractures $(1.6 \%)$.

The data for this retrospective study was based on residents of South Indian cities seeking treatment at Saveetha Dental College, Chennai, India. Currently there are no studies directly seeking to identify the same - to assess the need for suturing following maxillary third molar extractions. Since there was no filtration process involved, this study mostly remains free of bias in regard to the selection of patients - except for the exclusion of patients below the age of 20 years and above the age of 60 years, those with mental and physical disabilities and extractions left unreviewed which was classified as incomplete data. According to most studies, females are reported to have a higher incidence of third molar extractions when compared to males $[27,10,8]$. This is in accordance to our findings, where $52.7 \%$ of the total study population undergoing maxillary third molar extractions were females, followed by $47.3 \%$ of males and $0.1 \%$ of transgenders. In a study conducted by [32], they found a subject incidence of $57.3 \%$ of the study population to be females [32], which is comparable to our result of $52.7 \%$. To identify the incidence of the highest number of maxillary third molar extractions with respect to age, the patients of our study population aged (20-60) years were divided into four smaller age subsets: (20-30) years, (31-40) years, (41-50) years and (51-60) years. As inferred from Figure 1, the highest incidence of maxillary third molar extractions was seen in the age group of (31-40) years with $30.6 \%$ of the total extractions, followed by the age groups of both (20-30) years and (41-50) years with $26.9 \%$ each and lastly by the age group of (51-60) years with $15.6 \%$ of the total extractions. This data suggests that maxillary third mo-

Figure 1. Bar chart showing the frequency of extraction distribution among different age groups.

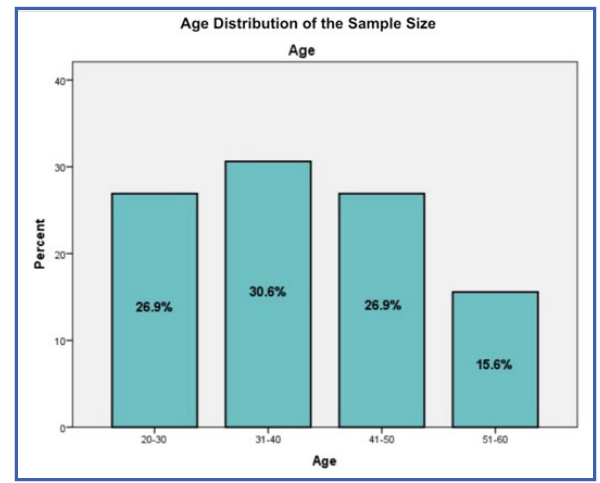

$\left[{ }^{*}\right.$ where the statistically significant incidence of maxillary third molar extractions is the highest in the age of (31-40) years and lowest in the age of $(51-60)$ years across the scale of percentage study population in the ' $y$ ' axis and age in the ' $x$ ' axis. (Chi Square Test, $p<0.05)$ ] 
Figure 2. Bar chart showing the frequency of third molar extractions according to gender.

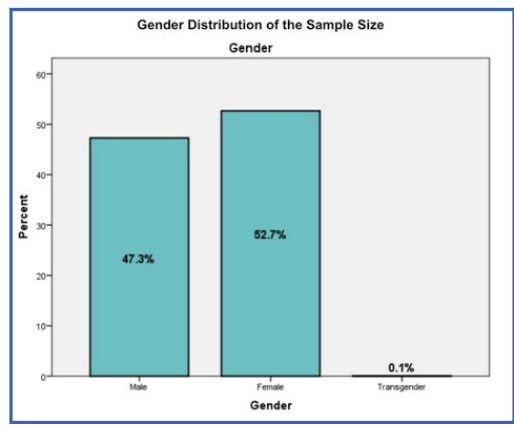

[*with a statistically significant female predilection of $52.7 \%$ across the scale of percentage study population in the ' $y$ ' axis and gender in the ' $x$ ' axis. (Chi Square Test, $\mathrm{p}<0.05)]$

Figure 3. Bar chart showing the distribution of involved tooth number - $18 \& 28 *$.

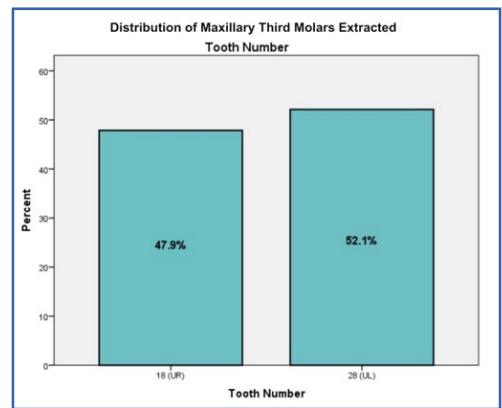

[*with a statistically significant predilection towards 28 over 18 across the scale of percentage study population in the ' $y$ ' axis and tooth number in the ' $\mathrm{x}$ ' axis. (Ch Square Test, $\mathrm{p}<0.05)]$

Figure 4. Bar chart showing the frequency of the population requiring suture placement*.

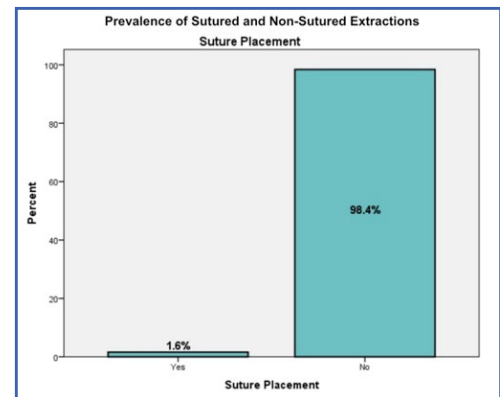

[*statistically significant across the scale of percentage study population in the ' $y$ ' axis and the placement of a suture in the ' $x$ ' axis. (Chi Square Test, $p<0.05)]$

Figure 5. Bar chart showing the distribution of complications involved*.

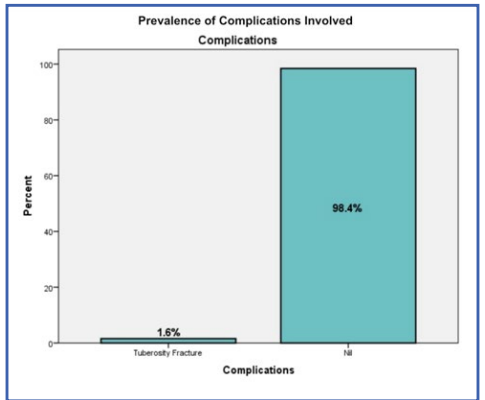

[*statistically significant with $1.6 \%$ being maxillary tuberosity fractures across the scale of percentage study population in the ' $y$ ' axis and complications in the ' $\mathrm{x}$ ' axis. (Chi Square Test, $\mathrm{p}<0.05)]$

lar extractions are commonly undergone between the age of 31 years and 40 years. This is inconsistent with a study performed by [31] where they concluded that (20-29) years is the most common age for third molar extractions. This contrast could be an attribute to the difference in number of individuals in each group in both the studies. But in this same study, they have suggested that the incidence of tuberosity fracture as a complication was $1.2 \%$ [31], which is in line with our finding of $1.6 \%$ for the same. In another study by [15], they suggest that the incidence of frac- ture during third molar removal alone is $0.6 \%$ [15], which is also in line with our results. The fracture of the maxillary tuberosity, an important retentive area for maxillary complete dentures [34], can even result - on rare occasions - in torrential haemorrhage due to its close proximity with significant blood vessels and other life-threatening complications (Bertram et al., 2011). In our study population, $1.6 \%$ of the total extractions were sutured because the same $1.6 \%$ of the cases had maxillary tuberosity fractures as complications of exodontia. The remaining $98.4 \%$ were left unsu- 
Table 1. Table showing the cross tabulation between suture placement and complications*.

\begin{tabular}{|c|c|c|c|c|c|}
\hline \multicolumn{2}{|c|}{ Count } & \multicolumn{2}{|c|}{ Complications } & \multirow{2}{*}{ Total } & \multirow{2}{*}{ P Value } \\
\cline { 3 - 4 } & Tuberosity Fracture & Nil & & \\
\hline \multirow{2}{*}{$\begin{array}{c}\text { Suture } \\
\text { Placement }\end{array}$} & Yes & 29 & 0 & 29 & \\
\cline { 2 - 4 } & No & 0 & 1807 & 1807 & \multirow{2}{*}{0.000} \\
\hline \multicolumn{2}{|c|}{ Total } & 29 & 1807 & 1836 & \\
\hline
\end{tabular}

[*statistically significant with $\mathrm{p}=0.000($ Chi Square Test, $\mathrm{p}<0.05)]$

tured because of the absence of complications. When comparing the incidence of extractions between the right [18] and left [28] maxillary third molars, 28 seemed to be more frequently extracted $(52.1 \%)$ when compared to $18(47.9 \%)$. Thus, our results pointed to a female predilection with a commonly affected age group of (31-40) years with 28 being more frequently extracted than 18 and maxillary tuberosity fractures (complications) caused the need for suturing following maxillary third molar extractions.

\section{Conclusion}

Within the limits of our study, there is a need for suturing only when complications such as maxillary tuberosity fractures are present, otherwise it is acceptable for it to even remain sutureless, with better prognosis, in fact. This is assuming that the individual undergoing the exodontia is not systemically compromised [22, 18] or prone to secondary health problems. Since the study does pose with certain limitations such as geographical barriers that lower the study's generalisability, further research must be done while actively trying to nullify said limitations.

\section{References}

[1]. Abhinav RP, Selvarasu K, Maheswari GU, Taltia AA. The Patterns and Etiology of Maxillofacial Trauma in South India. Ann Maxillofac Surg. 2019 Jan-Jun;9(1):114-117. Pubmed PMID: 31293938.

[2]. Alesia K, Khalil HS. Reasons for and patterns relating to the extraction of permanent teeth in a subset of the Saudi population. Clin Cosmet Investig Dent. 2013 Jul 30;5:51-6. Pubmed PMID: 23986651.

[3]. Abhinav RP, Selvarasu K, Maheswari GU, Taltia AA. The Patterns and Etiology of Maxillofacial Trauma in South India. Ann Maxillofac Surg. 2019 Jan-Jun;9(1):114-117. Pubmed PMID: 31293938.

[4]. Bertram AR, Rao AC, Akbiyik KM, Haddad S, Zoud K. Maxillary tuberosity fracture: a life-threatening haemorrhage following simple exodontia. Aust Dent J. 2011 Jun;56(2):212-5. Pubmed PMID: 21623815.

[5]. Brauer HU, Dent M, Green RA, Pynn BR. Complications during and after surgical removal of third molars. Mag Oral Health. 2013.

[6]. Bui CH, Seldin EB, Dodson TB. Types, frequencies, and risk factors for complications after third molar extraction. J Oral Maxillofac Surg. 2003 Dec;61(12):1379-89. Pubmed PMID: 14663801.

[7]. Christabel A, Anantanarayanan P, Subash P, Soh CL, Ramanathan M, Muthusekhar MR, et al. Comparison of pterygomaxillary dysjunction with tuberosity separation in isolated Le Fort I osteotomies: a prospective, multicentre, triple-blind, randomized controlled trial. Int J Oral Maxillofac Surg. 2016 Feb;45(2):180-5. Pubmed PMID: 26338075.

[8]. Eshghpour M, Nezadi A, Moradi A, Shamsabadi RM, Rezaei NM, et al. Pattern of mandibular third molar impaction: A cross-sectional study in northeast of Iran. Niger J Clin Pract. 2014 Nov-Dec;17(6):673-7. Pubmed PMID: 25385900

[9]. Hashemi HM, Beshkar M, Aghajani R. The effect of sutureless wound closure on postoperative pain and swelling after impacted mandibular third molar surgery. Br J Oral Maxillofac Surg. 2012 Apr;50(3):256-8. Pubmed PMID: 21636189

[10]. Hashemipour MA, Tahmasbi-Arashlow M, Fahimi-Hanzaei F. Incidence of impacted mandibular and maxillary third molars: a radiographic study in a Southeast Iran population. Medicina oral, patologia oral y cirugia bucal.
2013 Jan;18(1):e140.

[11]. Hollins C. Levison's Textbook for Dental Nurses. John Wiley \& Sons; 2019 Sep 10.

[12]. Vijayakumar Jain S, Muthusekhar MR, Baig MF, Senthilnathan P, Loganathan S, Abdul Wahab PU, et al. Evaluation of Three-Dimensional Changes in Pharyngeal Airway Following Isolated Lefort One Osteotomy for the Correction of Vertical Maxillary Excess: A Prospective Study. J Maxillofac Oral Surg. 2019 Mar; 18(1):139-146. Pubmed PMID: 30728705: PMC6328835.

[13]. Jerjes W, El-Maaytah M, Swinson B, Banu B, Upile T, D'Sa S, et al. Experience versus complication rate in third molar surgery. Head Face Med. 2006 May 25;2:14. Pubmed PMID: 16725024.

[14]. Jesudasan JS, Wahab PU, Sekhar MR. Effectiveness of $0.2 \%$ chlorhexidine gel and a eugenol-based paste on postoperative alveolar osteitis in patients having third molars extracted: a randomised controlled clinical trial. $\mathrm{Br} J$ Oral Maxillofac Surg. 2015 Nov;53(9):826-30. Pubmed PMID: 26188932.

[15]. Kandasamy S, Rinchuse DJ, Rinchuse DJ. The wisdom behind third molar extractions. Aust Dent J. 2009 Dec;54(4):284-92. Pubmed PMID: 20415925.

[16]. Kim JC, Choi SS, Wang SJ, Kim SG. Minor complications after mandibular third molar surgery: type, incidence, and possible prevention. Oral Surg Oral Med Oral Pathol Oral Radiol Endod. 2006 Aug;102(2):e4-11. Pubmed PMID: 16876044

[17]. Kumar, S. and Snena, S. Knowledge and awareness regarding antibiotic prophylaxis for infective endocarditis among undergraduate dental students, Asian J Pharm Clin Res. 2016.

[18]. Marimuthu M, Andiappan M, Wahab A, Muthusekhar MR, Balakrishnan A, Shanmugam S. Canonical Wnt pathway gene expression and their clinical correlation in oral squamous cell carcinoma. Indian J Dent Res. 2018 MayJun;29(3):291-297. Pubmed PMID: 29900911.

[19]. Mosha HJ, Lema PA. Reasons for tooth extraction among Tanzanians. East Afr Med J. 1991 Jan;68(1):10-4. Pubmed PMID: 2060474.

[20]. Kumar S. Relationship between dental anxiety and pain experience during dental extractions. Asian Journal of Pharmaceutical and Clinical Research. 2017;10(3):458.

[21]. Kumar $S$. The emerging role of botulinum toxin in the treatment of orofacial disorders: Literature update. Asian Journal of Pharmaceutical and Clinical Research. 2017;10(9):21-9.

[22]. Kumar S, Rahman RE. Knowledge, awareness, and practices regarding biomedical waste management among undergraduate dental students. Asian Journal of Pharmaceutical and Clinical Research. 2017;10(8):341.

[23]. Nice. Guidance on the extraction of wisdom teeth. National Institute for Clinical Excellence. 2000

[24]. Packiri S, Gurunathan D, Selvarasu K. Management of paediatric oral ranula: a systematic review. Journal of clinical and diagnostic research: JCDR. 2017 Sep;11(9):ZE06.

[25]. Patil SB, Durairaj D, Suresh Kumar G, Karthikeyan D, Pradeep D. Comparison of Extended Nasolabial Flap Versus Buccal Fat Pad Graft in the Surgical Management of Oral Submucous Fibrosis: A Prospective Pilot Study. J Maxillofac Oral Surg. 2017 Sep;16(3):312-321. Pubmed PMID: 28717289.

[26]. Patturaja K, Pradeep D. Awareness of Basic Dental Procedure among General Population. Research Journal of Pharmacy and Technology. 2016 Sep $1 ; 9(9): 1349$

[27]. Quek SL, Tay CK, Tay KH, Toh SL, Lim KC. Pattern of third molar impaction in a Singapore Chinese population: a retrospective radiographic survey. Int J Oral Maxillofac Surg. 2003 Oct;32(5):548-52. Pubmed PMID: 14759117.

[28]. Rahman RE, Mp SK. Knowledge, attitude, and awareness of dental undergraduate students regarding human immunodeficiency virus/acquired immunodeficiency syndrome patients. Asian J Pharm Clin Res [Internet]. 2017;10(5):175-80

[29]. Rao TD, Kumar MS. Analgesic efficacy of paracetamol vs ketorolac after dental extractions. Research Journal of Pharmacy and Technology. 2018 Aug $1 ; 11(8): 3375-9$. 
[30]. Reich E, Hiller KA. Reasons for tooth extraction in the western states of Germany. Community Dent Oral Epidemiol. 1993 Dec;21(6):379-83. Pubmed PMID: 8306617.

[31]. Sayed N, Bakathir A, Pasha M, Al-Sudairy S. Complications of Third Molar Extraction: A retrospective study from a tertiary healthcare centre in Oman. Sultan Qaboos Univ Med J. 2019 Aug;19(3):e230-e235. Pubmed PMID: 31728221

[32]. Susarla SM, Dodson TB. How well do clinicians estimate third molar extraction difficulty? J Oral Maxillofac Surg. 2005 Feb;63(2):191-9. Pubmed PMID: 15690287.

[33]. Sweta VR, Abhinav RP, Ramesh A. Role of virtual reality in pain perception of patients following the administration of local anesthesia. Annals of maxillofacial surgery. 2019 Jan;9(1):110.

[34]. Venkateshwar GP, Padhye MN, Khosla AR, Kakkar ST. Complications of exodontia: a retrospective study. Indian J Dent Res. 2011 SepOct;22(5):633-8. Pubmed PMID: 22406704.

[35]. Zadik Y, Sandler V, Bechor R, Salehrabi R. Analysis of factors related to extraction of endodontically treated teeth. Oral Surg Oral Med Oral Pathol Oral Radiol Endod. 2008 Nov;106(5):e31-5. Pubmed PMID: 18718782. 